\title{
ANALISIS SOSIO KULTURAL PETANI NANAS (ANANAS COMOSUS) DI DESA TANJUNG BATU KABUPATEN OGAN ILIR
}

\begin{abstract}
(Aminullah)
Abstract

The purpose of this research were to : (1) To determine the perception of farmers Pineapple (Ananas comosus) on farm Pineapple (Ananas comosus) at Tanjung Batu district of Tanjung Batu Ogan Ilir, (2) Determine how the analysis of the feasibility of farming Pineapple (Ananas comosus) The village of Tanjung Batu district of Tanjung Batu Ogan Ilir. This research was conducted in June 2015 by the survey. This study found that the perception of farmers on the availability of supporting infrastructure and facilities provided in order to smooth the absolute namely pineapple farm with a total score of 71 and a percentage of $61.74 \%$, while for the farmer's perception that the experience was a factor of the success in pineapple farming is by total score 83 and a percentage of $72.17 \%$ for the farmer's perception that the extension is needed in the pineapple farm in the village of Tanjung Batu with a total score of 57 with a percentage of $49.57 \%$, and the NPV value is Rp 12.10902 million, the IRR is equal to 29,03\% and Net B / C of 1.13 then this shows that pineapple farming in the village of Tanjung Batu district of Tanjung Batu Ogan Ilir profitable and feasible (feasible) to be developed.
\end{abstract}

Key Words : Socio Cultural, Ananas Comosus, Income.

\section{PENDAHULUAN}

\section{A. Latar Belakang}

Perkebunan adalah segala kegiatan yang mengusahakan tanaman tertentu pada tanah dan atau media tumbuh lainnya dalam ekosistem yang sesuai, mengolah, dan memasarkan barang dan jasa hasil tanaman tersebut, dengan bantuan ilmu pengetahuan dan teknologi, permodalan serta manajemen untuk mewujudkan kesejahteraan bagi pelaku usaha perkebunan dan masyarakat. Tanaman yang ditanam bukanlah tanaman yang menjadi makanan pokok maupun sayuran untuk membedakannya dengan usaha ladang dan hortikultura sayur mayur dan bunga, meski usaha penanaman pohon buah masih disebut usaha perkebunan (Nuhfil, 2006).

Peran Indonesia sebagai produsen maupun eksportir Nanas (Ananas comosus) segar di pasar internasional masih sangat kecil. Indonesia menempati posisi yang ketiga dari negara-negara penghasil Nanas olahan dan segar setelah negara Thailand dan Filipina. Didalam daya saing ekspor Nanas segar Indonesia berdasarkan pangsa pasarnya relatif masih kecil dibandingkan produsen dan eksportir Nanas segar lainnya. Komoditi Nanas telah lama dibudidayakan di Indonesia, dan di pasar domestik banyak dijual dan dikonsumsi dalam bentuk segar, tetapi untuk preferensi konsumen internasional sendiri adalah Nanas olahan. Selama tahun 2000-2005 perkembangan produksi Nanas Indonesia rata-rata sebesar 6.145.382 ton dengan sedikit berfluktuasi, produksi tertinggi sebesar 925 ribu ton terjadi pada tahun 2005 (Badan Pusat Statistika, 2005).

Menurut data Badan Pusat Statistik (BPS), volume ekspor Nanas, baik segar maupun kalengan pada Januari hingga Oktober 2011 mencapai 161.386 ton senilai US\$ 173,89 juta, naik 29,48\% ketimbang periode sama tahun 2010. Total produksi Nanas Indonesia yang mencapai 1,5 juta ton pada tahun 2011, sebanyak 90\% adalah nanas jenis queen, sedangkan sisanya atau hanya $10 \%$ berjenis smooth cayenne. Total ekspor Nanas (yang terbagi dalam nenas segar dan nenas olahan), ekspor terbesar untuk Nanas segar ditujukan ke negara Malaysia dengan share $74 \%$, sementara ke Jepang 24,54\%. Sementara untuk Nanas olahan terbesar berturut-turut adalah ke negara Amerika Serikat (22,62 \%), Belanda $(15,19 \%)$, Singapura $(13,94 \%)$, Jerman $(13,86 \%)$, dan Spanyol (10,58 \%). Rata-rata volume ekspor ke Amerika sejak tahun 19992005 sebesar 52.054 ton dan relatif stabil setiap tahunnya, tetapi ekspor ke negara Belanda, Singapura dan Jerman serta Spanyol terus menunjukkan trend yang meningkat. Buah Nanas juga memiliki banyak kandungan seperti vitamin $\mathrm{B}$, vitamin $\mathrm{C}$, fosfor, magnesium, natrium, dekstrosa, sukrosa, serta enzim bromelain. Selain itu, beberapa negara mengonsumsi Nanas untuk mencegah serangan jantung, beri-beri, stroke dan masih banyak lagi penyakit lainnya.Tujuan ekspor adalah Perancis, Jerman, dan Amerika Serikat. Walaupun daerah penghasil Nanas sudah menyebar merata, Indonesia hingga saat ini hanya 
mampu mengekspor sebagian kecil saja dari kebutuhan dunia, 5\%. Untuk memenuhi kebutuhan ini diperlukan pasokan Nanas yang sangat besar. Tentu saja hal ini akan menjadi prospek dan peluang pasar yang baik bagi Indonesia (Data BPS, Litbang, data diolah F. Hero dan K. Puba, 2001).

Pemahaman budidaya yang baik dan pemanfaatan teknologi yang efisien tentu akan dapat memenuhi standar permintaan konsumen. Dengan begitu maka para petani nanas dapat menyejahterakan kehidupan keluarganya (Tim Karya Tani Mandiri, 2010).

Tanaman Nanas (Ananas comosus) memberikan prospek yang cerah dalam membantu meningkatkan produksi hasil pertanian terutama dalam pemenuhan kebutuhan tanaman pangan. Upaya pengembangan tanaman Nanas (Ananas comosus) terus dilakukan melalui berbagai kegiatan antara lain usaha peningkatan kualitas produk (Intensifikasi) dan perluasan areal tanam (Ekstensifikasi) maupun penganekaragaman tanaman. Pengembangan usaha hortikultura perlu didasarkan pada perhitungan yang cermat serta dilihat secara keseluruhan sebagai satu sistem Agribisnis, yaitu menyangkut industri pengadaan dan penyaluran sarana produksi, usahatani, industri pengolahan dan pemasaran. Hal tersebut perlu diperhatikan karena dalam usaha agribisnis hortikultura memerlukan penanaman modal yang cukup besar dan beresiko tinggi. Industri pengolahan hortikultura merupakan alternatif pembangunan pertanian yang diharapkan dapat memberikan dampak yang positif yang mampu mendorong pembangunan di sektor lain dan peningkatan perolehan devisa.

Pembangunan sub sektor hortikultura terdiri dari komoditi buah-buahan, sayuran dan tanaman hias serta obat-obatan sangat potensial sebagai salah satu sumber pertumbuhan ekonomi di masa depan. Hal ini sangat beralasan karena keempat kelompok komoditi hortikultura tersebut memiliki potensi yang relatif lebih besar dibandingkan dengan komoditas pangan lainnya. Potensi tersebut meliputi aspek sumberdaya alam seperti lahan, agroklimat dan topografi, nilai ekonominya, kemampuan menyerap tenaga kerja dan dapat digunakan sebagai unsur pendukung konservasi lahan serta menambah nilai estetika. Nanas (Ananas comosus) merupakan salah satu komoditi hortikultura yang telah lama dibudidayakan dan memiliki prospek serta potensi untuk terus dikembangkan.

Peran penting sektor pertanian telah terbukti dari keberhasilan sektor pertanian pada saat krisis ekonomi dalam menyediakan kebutuhan pangan pokok dalam jumlah yang memadai dan tingkat pertumbuhannya yang positif dalam menjaga laju pertumbuhan ekonomi nasional. Keadaan ini menjadi pertimbangan utama dirumuskannya kebijakan yang memiliki keberpihakan terhadap sektor pertanian dalam memperluas lapangan kerja, menghapus kemiskinan dan mendorong pembangunan ekonomi yang lebih luas (Sudaryanto dan Munif, 2005).

Secara geografis Kabupaten Ogan Ilir terletak diantara $30^{\circ}-48^{0}$ Lintang Selatan dan diantara $20^{\circ}-48^{0}$ Bujur Timur, luas wilayahnya adalah 251.309 Ha. Perbatasan wilayahnya adalah di sebelah timur berbatasan dengan Kabupaten Banyuasin, Kabupaten Ogan Komering Ilir, dan Kabupaten Ogan Komering Ulu Timur, di sebelah barat berbatasan dengan Kabupaten Muara Enim dan Kabupaten Bayuasin, di sebelah utara berbatasan dengan Kota Palembang, dan di sebelah selatan berbatasan dengan Kabupaten Ogan Komering Ulu, wilayah ini terbagi atas 16 Kecamatan, 13 Kelurahan dan 227 Desa. Kabupaten Ogan Ilir merupakan daerah yang mempunyai iklim Tropis Basah dengan musim kemarau. Curah hujan disuatu wilayah dipengaruhi oleh keadaan iklim, geografi, dan perputaran/pertemuan arus udara. Oleh karena itu jumlah curah hujan beragam menurut bulan dan letak stasiun pengamat. Pada tahun 2007 (dari 3 kecamatan yang memiliki alat pendeteksi hujan), rata-rata curah hujan per tahun berkisar antara $168,83 \mathrm{~mm}$ sampai 197,75 $\mathrm{mm}$ (BPS Provinsi Sumatera Selatan, 2013).

Mayoritas penduduk Kabupaten Ogan Ilir terutama di Desa Tanjung Batu yaitu dengan berprofesi sebagai petani. Menurut Data Analisis (2013) wilayah Kabupaten Ogan Ilir mempunyai sektor pertanian buah-buahan dengan potensi komoditas unggulan yaitu Nanas (Ananas comosus). Maka dari itu diperlukan dukungan untuk pengembangan komoditas Nanas (Ananas comosus) kearah perubahan bagi orientasi produksi kearah peningkatan pendapatan petani dan untuk mewujudkan perubahan tersebut diperlukan suatu sistem usahatani yang tepat, diperlukan peningkatan pengetahuan dan ketrampilan dalam mengenali potensi, menyusun rencana usahatani, mengatasi permasalahan, mengambil keputusan dan menerapkan teknologi yang sesuai dengan komdisi sumber daya alam setempat secara sinergi dan berwawasan lingkungan, sehingga usahataninya menjadi 
efisien, mempunyai produktivitas yang maksimal dan berkelanjutan.

\section{B. Rumusan Masalah}

1. Bagaimana persepsi Nanas (Ananas comosus) terhadap usahatani Nanas (Ananas comosus) di Desa Tanjung Batu Kecamatan Tanjung Batu Kabupaten Ogan Ilir.

2. Bagaimana analisis kelayakan usahatani Nanas (Ananas comosus) di Desa Tanjung Batu Kecamatan Tanjung Batu Kabupaten Ogan Ilir.

\section{Tujuan dan Kegunaan}

1. Untuk mengetahui persepsi petani Nanas (Ananas comosus) terhadap usahatani Nanas (Ananas comosus) di Desa Tanjung Batu Kecamatan Tanjung Batu Kabupaten Ogan Ilir.

2. Mengetahui bagaimana analisis kelayakan usahatani Nanas (Ananas comosus) di Desa Tanjung Batu Kecamatan Tanjung Batu Kabupaten Ogan Ilir.

\section{Model Pendekatan}

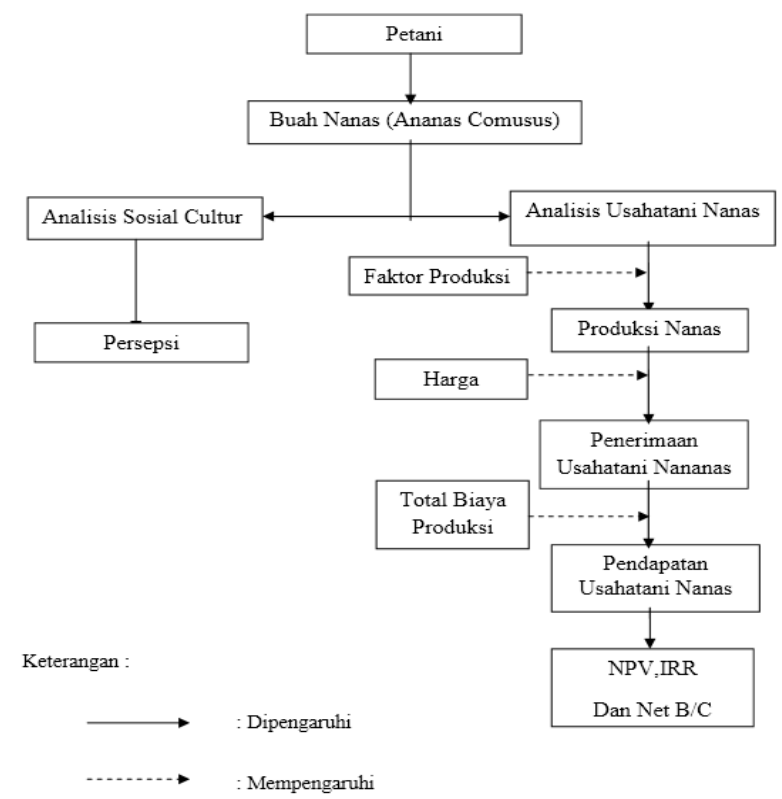

Gambar 1. Model pendekatan penelitian secara diagramatik

\section{METODOLOGI PENELITIAN}

\section{A. Tempat dan Waktu}

Penelitian ini dilaksanakan di Desa Tanjung Batu Kecamatan Tanjung Batu Kabupaten Ogan Ilir. Penentuan lokasi ini dilakukan secara sengaja dengan pertimbangan bahwa di Desa Tanjung Batu Kecamatan Tanjung Batu Kabupaten Ogan Ilir mempunyai letak geografis wilayah yang mendukung bagi pengembangan komoditi unggulan Nanas (Ananas comosus) ke arah perubahan yang berorientasi peningkatan pendapatan petani sehingga dapat menyejahterakan kehidupan keluarga petani. Pengumpulan data primer dan data sekunder dalam penelitian ini telah dilaksanakan pada bulan Juni 2015.

\section{B. Metode Penelitian}

Metode yang digunakan dalam penelitian ini adalah metode suvei terhadap petani Nanas (Ananas comosus) yang berada di Desa Tanjung Batu Kecamatan Tanjung Batu Kabupaten Ogan Ilir. Tujuaan penelitian adalah mempelajari secara intensif tentang latar belakang sosio kultural petani Nanas (Ananas comosus), faktor-faktor yang mempengaruhi produksi, pendapatan dan interaksi lingkungan suatu unit sosial seperti : individu, kelompok, lembaga serta masyarakat.

\section{Metode Penarikan Contoh}

Metode penarikan contoh dilakukan dengan menggunakan teknik Probability sampling yaitu pengambilan sampel yang memberikan peluang yang sama setiap unsur atau anggota untuk dipilih menjadi anggota sampel. Teknik Probability yang digunakan adalah teknik Simple Random Sampling, teknik ini digunakan bila populasi mempunyai anggota/unsur yang tidak sama.

Menurut Boediono (2010) untuk mencari n (sampel) dari $\mathrm{N}$ (populasi) adalah dengan rumus sebagai berikut :

$$
n=\frac{N}{1+N\left(e^{2}\right)}
$$

Keterangan :

$$
\begin{aligned}
& \mathrm{n}=\text { Sampel } \\
& \mathrm{N}=\text { Populasi } \\
& \mathrm{E}=\text { Tingkat Eror }(0,15)
\end{aligned}
$$

Dalam menentukan sampel, peneliti menggunakan tingkat kesalahan sebesar $15 \%$. Berdasarkan data yang ada dilapangan terdapat 49 pelaku usahatani Nanas sehingga sampel yang diambil sebanyak 23 petani Nanas.

\section{Metode Pengolahan Data}

Data yang telah diperoleh dari lapangan dikelompokkan diolah secara tabulasi. Menurut Sugiyono (2004), untuk menjawab hipotesis nomer satu yaitu dengan menggunakan Skala Likert. Skala Likert digunakan untuk mengukur sikap, dan persepsi seseorang atau kelompok orang tentang fenomena. Jawaban setiap item instrument yang menggunakan skala Likert 
mempunyai gradasi sari sangat positif hingga negatif. Data dari pertanyaan dengan skala Likert ,tersebut kemudian dianalisa berdasarkan skor setiap jawaban dari responden (tingkat persetujuan), maka digunakan rumus :

\section{$\frac{\text { SkorTotal Jawaban Responden }}{\text { Skorldeal }} \times 100 \%$}

$\begin{array}{crrr}\text { Menurut } & \begin{array}{c}\text { Sugiyono } \\ \text { menanggapi }\end{array} & \begin{array}{r}(2004), \\ \text { dalam }\end{array} & \begin{array}{c}\text { dalam } \\ \text { skala }\end{array}\end{array}$ Likert, responden menentukan tingkat persetujuan mereka terhadap suatu pernyataan dengan memilih salah satu dari pilihan yang tersedia. Ada dua bentuk pertanyaan yang menggunakan Likert yaitu pertanyaan positif untuk mengukur minat positif, dan bentuk pertanyaan negatif untuk mengukur minat negatif.

Biasanya disediakan lima pilihan skala dengan format seperti:

Tabel 1. Pengukuran pilihan skala likert

\begin{tabular}{llcc}
\hline No & Pendapat & Skor Positif & Skor Negatif \\
\hline 1. & Sangat tidak setuju & 1 & 5 \\
2. & Tidak setuju & 2 & 4 \\
3. & Netral & 3 & 3 \\
4. & Setuju & 4 & 2 \\
5. & Sangat setuju & 5 & 1 \\
\hline
\end{tabular}

Sumber : Sugiyono, 2009

Setelah melakukan perhitungan menggunakan Skala Likert maka selanjutnya dihitung menggunakan Uji Validitas. Uji validitas dilakukan untuk mengetahui sampai sejauh mana ketepatan dan ketelitian antara hasil pengukuran dari variabel yang diteliti dengan teori. Hasil penelitian dikatakan valid apabila terdapat kesamaan antara data yang terkumpul dengan data yang sesungguhnya terjadi pada objek yang diteliti.

Menurut Arikunto (2002) untuk pengujian tingkat validitas instrumen dalam penelelitian ini dengan membandigkan indek korelasi produk moment ( $r$ hitung) dengan rumus sebagai berikut :

$$
r_{X Y}=\frac{n \sum x y-\left(\sum x\right)\left(\sum y\right)}{\sqrt{\left(n \sum x^{2}-\left(\sum x\right)^{2}\left(n \sum y^{2}\right)-\left(\sum y\right)^{2}\right)}}
$$

Dimana :

$r_{x y}=$ koefisien korelasi Pearson

$\mathrm{n}=$ Jumlah Subyek

$\mathrm{x} \quad=$ Total Skor Variabel Bebas

$\mathrm{y} \quad=$ Total Skor Variabel Terikat

Menurut Suratiyah (2006), guna menjawab hipotesis ke dua untuk menghitung kelayakan maka harus menghitung dulu jumlah biaya produksi, penerimaan dan pendapatan digunakan rumus sebagai berikut :

1. $\mathrm{TC}=\mathrm{FC}+\mathrm{VC}$

Dimana :

$\mathrm{TC}=$ Total Cost $($ Biaya Total $)$

$\mathrm{FC}=$ Fixed Cost (Biaya Tetap)

$\mathrm{VC}=$ Variabel Cost (Biaya Variabel $)$

2. $\mathrm{TR}=\mathrm{P} \times \mathrm{Q}$

Dimana :

$\mathrm{TR}=$ Total Revenues (Penerimaan)

$\mathrm{P}=$ Prince (Harga Komoditas dalam Rupiah) quantum

$\mathrm{Q}=$ Quantum (Jumlah Produksi)

3. $\pi=\mathrm{TR}-\mathrm{TC}$

Dimana :

$\pi=($ Pendapatan $)$

4. $\mathrm{R} / \mathrm{C}$ Ratio $=\frac{\mathrm{TR}}{\mathrm{TC}}$

Dimana :

$\mathrm{R} / \mathrm{C}=$ Return Cost Ratio

$\mathrm{TR}=$ Total Revenues $($ Penerimaan $)$

$\mathrm{TC}=$ Total Cost $($ Biaya Total $)$

Dengan Kriteria :

$\mathrm{R} / \mathrm{C}>1$ berarti maka usaha tersebut menguntungkan.

$\mathrm{R} / \mathrm{C}=1$ berarti usaha tidak untung dan tidak rugi (Impas).

$\mathrm{R} / \mathrm{C}<1$ berarti maka usaha tersebut tidak menguntungkan (Rugi).

Menurut Ibrahim(2009), untuk nilai kelayakan finansial digunakan rumus sebagai berikut :

Dimana :

$$
\mathrm{NPV}=\sum_{i=1}^{n} \mathrm{NB} \mathrm{i}(1+i)^{-n}
$$

$\mathrm{NPV}=$ Net PresentValue

$\mathrm{NB}=$ Net Benefit (Benefit - Cost) Pendapatan Bersih

$\mathrm{i}=$ Discount Faktor

$\mathrm{n}=$ Tahun (Waktu)

Untuk menghitung Internal Rate Ratio

(IRR) maka digunakan rumus :

$$
I R R=i_{1}+\frac{N P V_{1}}{\left(N P V_{1}-N P V_{2}\right)} X\left(i_{2}-i_{1}\right)
$$

Dimana:

NPV1 = NPV pada tingkat discount rate tertinggi (positif)

NPV2 = NPV pada tingkat discount rate terendah (negatif)

$\mathrm{i}_{1} \quad=$ Tingkat discount rate yang menghasilkan NPV1 
$\mathrm{i}_{2}=$ Tingkat discount rate yang menghasilkan NPV2

Untuk menghitung nilai Net $\mathrm{B} / \mathrm{C}$ maka digunakan rumus:

$$
\text { Net } B / C=\frac{\sum_{i=1}^{n} N \bar{B} i(+)}{\sum_{i=1}^{n} N \bar{B} i(-)}
$$

Dimana :

Net $B / C>0$ berarti usaha tersebut layak

dikembangkan

Net $\mathrm{B} / \mathrm{C}=0$ berarti usaha tidak untung tidak

rugi (impas)

Net $B / C<0$ berarti usaha tidak

menguntungkan (rugi).

\section{HASIL DAN PEMBAHASAN}

\section{A. Analisis Biaya, Penerimaan, dan Pendapatan Produksi Usahatani Nanas}

1. Analisis Biaya Produksi Usahatani Nanas

Total biaya adalah semua biaya yang digunakan dalam usahatani nanas yang meliputi biaya tetap dan biaya variabel. Biaya tetap adalah biaya yang besarnya tidak dipengaruhi oleh jumlah produksi, yang meliputi biaya sewa lahan per hektar yaitu sebesar Rp 20.000.000 per Ha, total biaya investasi yaitu dari tahun 2013 - 2015 termasuk pembelian peralatan seperti tangki, tugal sarung tangan dan lainnya menghabiskan biaya sebesar Rp 12.499.682 MT/Ha

Biaya variabel adalah biaya yang besar kecilnya tergantung kepada besar kecilnya produksi dan akan habis dalam satu kali proses produksi. Biaya variabel dalam usahatani nanas ini meliputi biaya saprodi dan tenaga kerja. Adapun biaya operasional meliputi : penyemprotan, pupuk ponska, pupuk urea, bibit nanas, sheva, karbit dan lainya yaitu sebesar Rp 13.148.699 MT/Ha. Rata- rata besarnya biaya total produksi usahatani nanas per hektar dari tahun 2013 - 2015 yang terdiri atas biaya investasi dan juga biaya operasional adalah sebesar Rp 25.648.381 MT/Ha. Besarnya biaya yang dipergunakan pada usahatani nanas dapat dilihat pada tabel berikut.

Tabel 2. Total biaya Produksi Usahatani Nanas di Desa Tanjung Batu

\begin{tabular}{llr}
\hline No & Uraian & $\mathrm{Rp} / \mathrm{Ha} / \mathrm{MT}$ \\
\hline 1. & Biaya Investasi & 12.499 .682 \\
2. & Biaya Operasional & 13.148 .699 \\
\hline 3 & Total Biaya & 25.648 .381 \\
\hline
\end{tabular}

Sumber : Hasil Olahan Data Primer, 2013-2015.

\section{Penerimaan dan Pendapatan}

Penerimaan merupakan perkalian antara total produk yang terjual dengan harga persatuan produk. Penerimaan usahatani nanas semua berasal dari buah nanas yang terjual. Buah nanas pokok yang dijual responden rata-rata dipanen pada saat nanas mencapai umur 16 bulan dari proses penanaman. Lebih jelasnya mengenai jumlah produksi, harga dan penerimaan dari usahatani nanas di Desa Tanjung Batu Kecamatan Tanjung Batu Kabupaten Ogan Ilir dapat dilihat pada tabel berikut :

Tabel 3. Total Produksi, Harga, Penerimaan dan Pendapatan usahatani nanas di Desa Tanjung Batu Kecamatan Tanjung Batu Kabupaten Ogan Ilir, 2015.

\begin{tabular}{|c|c|c|c|}
\hline No & Uraian & Jumlah & \\
\hline & & & Satuan \\
\hline 1 & Produksi & 42.162 & Buah/Ha/MT \\
\hline \multirow[t]{4}{*}{2} & Harga & & \\
\hline & - Buah & 2.000 & Rp/buah \\
\hline & Pokok & 1.700 & \\
\hline & $\begin{array}{l}- \text { Buah } \\
\text { ke Dua }\end{array}$ & & \\
\hline 3 & Penerimaan & 156.000 .043 & $\mathrm{Rp} / \mathrm{Ha} / \mathrm{MT}$ \\
\hline 4 & $\begin{array}{l}\text { Total Biaya } \\
\text { Produksi }\end{array}$ & 25.648.381 & $\mathrm{Rp} / \mathrm{Ha} / \mathrm{MT}$ \\
\hline 5 & Pendapatan & 143.500 .362 & $\mathrm{Rp} / \mathrm{Ha} / \mathrm{MT}$ \\
\hline
\end{tabular}

Pada tabel diatas menunjukan bahwa ratarata produksi nanas per ha menghasilkan 42.162 buah dengan harga antara Rp. 2000 untuk harga nanas pokok sedangkan untuk harga Rp. 1700 untuk harga nanas yang sudah panen ke 2 dari batang nanas yang ada, sehingga akan menghasilkan total penerimaan yaitu tahun 20132015 adalah sebesar Rp 156.000.043 MT/Ha.

Pendapatan atau keuntungan yang diperoleh dari usahatani nanas merupakan selisih antara penerimaan dengan biaya total. Nilai pendapatan ini merupakan hasil bersih yang diperoleh selama proses produksi. Total Biaya produksi nanas adalah sebesar Rp. 25.648.381 MT/Ha, selama masa tanam proses produksi akan diperoleh ratarata pendapatan sebesar Rp. 143.500.362 MT/Ha.

\section{B. Analisa Kelayakan Usahatani Nanas di Desa Tanjung Batu. \\ Analisa NPV dan IRR \\ Net Present Value (NPV) atau nilai sekarang bersih adalah analisis manfaat finansial}


yang digunakan untuk mengukur layak tidaknya suatu usaha dilaksanakan dilihat dari nilai sekarang (present value). Keuntungan dari suatu proyek adalah besarnya penerimaan dikurangi pembiayaan yang dikeluarkan. Dapat dikatakan bahwa NPV adalah selisih antara Present Value dari arus Benefit dikurangi Present Value dari arus biaya (Soekartawi, 1996). Dalam kriteria ini dikatakan bahwa proyek akan dipilih apabila nilai NPV lebih besar dari nol. Kesimpulannya jika suatu proyek mempunyai NPV kurang dari nol, maka tidak akan dipilih atau tidak layak untuk dijalankan atau proyek layak jika NPV bertanda positif dan sebaliknya tidak layak jika NPV bertanda negatif.

IRR menunjukkan kemampuan suatu investasi atau usaha dalam menghasilkan return atau tingkat keuntungan yang bisa dipakai. Kriteria yang dipakai untuk menunjukkan bahwa suatu usaha layak dijalankan adalah jika nilai IRR lebih besar dari tingkat suku bunga yang berlaku pada saat usahatani tersebut diusahakan (Gittinger, 1993). Jadi, jika IRR lebih tinggi dari tingkat bunga bank, maka usaha yang direncanakan atau yang diusulkan layak untuk dilaksanakan. . Lebih jelasnya mengenai NPV dan IRR dari usahatani nanas dalam kurun waktu lima tahun yaitu tahun 2013 sampai dengan tahun 2015 di Desa Tanjung Batu Kecamatan Tanjung Batu Kabupaten Ogan Ilir dapat dilihat pada Tabel berikut :

Tabel 4. Kelayakan usahatani Nanas di Desa Tanjung Batu Kecamatan Tanjung Batu Kabupaten Ogan Ilir.

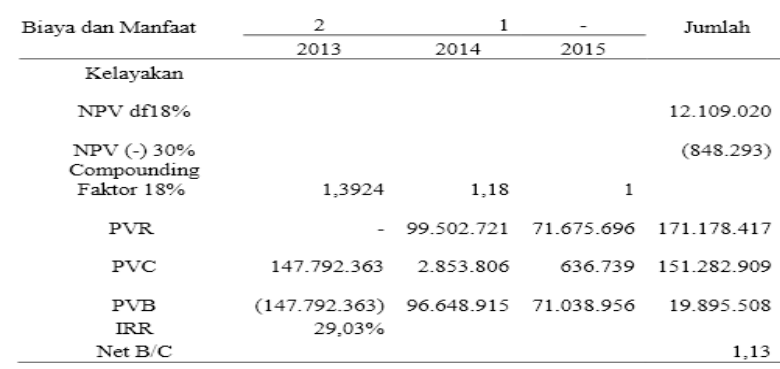

Sumber : Hasil olahan Data Primer, 2013- 2015.

Hasil analisis pada tabel diatas diperoleh perhitungan NPV selama lima tahun yaitu dari tahun 2013 - 2015 dengan tingkat bunga $18 \%$ maka diperoleh nilai NPV adalah sebesar Rp 12.109.020 dan nilai NPV >0, dengan demikian dapat diartikan bahwa usahatani nanas ini menguntungkan dan layak untuk dikembangkan

Berdasarkan hasil perhitungan diatas, diperoleh nilai IRR adalah sebesar $29,03 \%$ yang berarti nilai IRR lebih besar dari nilai suku bunga bank (SOCC) sebesar 18\%. Hal ini menunjukan bahwa usahatani nanas di Desa Tanjung Batu
Kecamatan Tanjung Batu Kabupaten Ogan Ilir menguntungkan dan layak (feasible) untuk dikembangkan.

Berdasararkan hasil tabel diatas, maka diperoleh nilai Net B/C adalah sebesar 1,13 yang berarti nilai Net $\mathrm{B} / \mathrm{C}$ lebih besar dari satu, berarti usahatani nanas tersebut menguntunkan dab layak untuk dikembangkan setelah mengalami coumpounding faktor sebesar $18 \%$ karena setiap investasi yang dikeluarkan sebesar Rp. 1 untuk usahatani nanas di Desa Tanjung Batu maka akan memperoleh keuntungan sebesar Rp. 1,13.

\section{IV.KESIMPULAN DAN SARAN}

\section{A. Kesimpulan}

Berdasarnya hasil penelitian dan analisis yang telah dilakukan, maka dapat ditarik kesimpulan sebagai berikut:

1. Persepsi petani terhadap ketersediaan sarana dan prasarana pendukung mutlak tersedia guna kelancaran usahatani nanas yaitu dengan total skor sebesar 71 dan persentase $61,74 \%$, sedangkan untuk persepsi petani bahwa pengalaman itu merupakan factor yang menunjang keberhasilan dalam usahatani nanas yaitu dengan total skor 83 dan persentase sebesar $72,17 \%$ untuk persepsi petani bahwa penyuluh itu sangat dibutuhkan dalam usahatani nanas di Desa Tanjung Batu dengan total skor 57 dengan persentase sebesar $49,57 \%$.

2. Rata-rata hasil uji validitas diperoleh nilai diatas standar nilai $r$ tabel yaitu 0.389 untuk 23 responden. Semua item pertanyaan dengan nilai korelasi antara item dengan skor total lebih dari $r$ tabel maka berdasarkan penentuan uji validitas maka dapat disimpulkan bahwa semua pertanyaan valid

3. Nilai NPV adalah sebesar Rp 12.109.020, nilai IRR adalah sebesar 29,03\% dan Net B/C sebesar 1,13 maka hal ini menunjukan bahwa usahatani Nanas di Desa Tanjung Batu Kecamatan Tanjung Batu Kabupaten Ogan Ilir menguntungkan dan layak (feasible) untuk dikembangkan.

\section{B. Saran}

1. Petani sebaiknya dapat memaksimalkan usahatani nanas dengan menggunakan benih unggul, serta pemupukan dan penggunaan zat pengendali tanaman yang sesuai dengan kebutuhan nanas, sehingga kuantitas nanas 
yang dihasilkan lebih meningkat dan pendapatan yang diperolehpun akan lebih tinggi.

2. Pemerintah hendaknya memberikan perhatian yang lebih pada usahatani nanas mengingat kebutuhan konsumsi buah nanas semakin meningkat, dan juga potensi pasar yang dimiliki masih terbuka luas.

3. Perhatian pemerintah dapat diwujudkan dengan memberikan penyuluhan mengenai usahatani nanas atau memberikan bantuan yang berupa modal untuk berusahatani nanas dan lebih meningkatkan peran dari kelompok tani dengan membentuk atau mendirikan koperasi pedagang nanas yang diantara anggotanya adalah kelompok tani tersebut.

\section{DAFTAR PUSTAKA}

Ahmadi, A. 2004. Psikologi Belajar. PT. Rineka Cipta. Jakarta.

BPS. 2005. Badan Pusat Statistika Tentang Nanas. Jakarta.

Anonim.2010.“Nanas”,www.wikipedia.com/deskr ipsi-nanas.html diakses pada tanggal 29 april 2015

Arikunto, Suharsimi. 2002. Prosedur Penelitian suatu Pendekatan Praktek. Rineka Cipta. Jakarta.

Ball. 2000. Bisnis Internasional. Salemba Empat. Jakarta.

Dalimartha, S. 2001. Atlas Tumbuhan Obat Indonesia Jilid 2. Nanas. h. 140-. 145. Trubus Agriwidya. Jakarta.

Daniel, Mosher. 2002. Metode Penelitian Sosial Ekonomi di Lengkapi Beberapa Alat Dan Analisa dan Penuntut Pengguna. Jurnal Ilmi-ilmu Pertanian. Vol. 5, No 1, pp. 1-21

Effendy. (1998). Dasar-dasar kesehatan masyarakat. Jakarta: Penerbit Buku Kedokteran EGC

Gibson, J. L. 2000. Organisasi dan Manajemen : Perilaku Struktur Proses. Erlangga.

Hadisapoetra, S. 2003. Biaya Dan Pendapatan Di Dalam Usahatani. Departemen Ekonomi Fakultas Pertanian. UGM. Yogyakarta.

Umar, Husein. 2002. Metode Riset Bisnis. PT. Gramedia Pustaka Utama. Jakarta.

Ibrahim, Y. 2009. Study Kelayakan Bisnis. Rineka. Jakarta.

Kartasoepatra, A.G. 2006. Pengantar Ekonomi Produksi. Bina Aksana. Jakarta.
Linbong, W.H dan P. Sitorus, 2005. Pengantar Tata Niaga Pertanian. Jurusan Ilmu Social Ekonomi Pertanian. Institut Pertanian Bogor. Bogor

Muftiadi, A. Pengantar Ilmu Ekonomi. Kareka, Bandung.

Nuhfil, 2006. Strategi Pembangunan Pertanian. PT Bhratara Karya Aksara. Jakarta

Prasetya, p. 2006. Ilmu Usahatani II. Fakultas Pertanian. UNS. Surakarta

Rakhmat, J. 2007. Persepsi Dalam Proses Belajar Mengajar. Rajawali Pers. Jakarta.

Rakhmat, J. 1998. Psikologi Komunikasi. PT. Remaja Rosdakarya. Bandung.

Ruch, Floyd L. 1967. Psychology and Life, 7 Edt. Scott. Foresman and Company. Atlanta.

Saragih. 1998. Pertanian Modern. Raja Grafindo Persada. Jakarta.

Sjarkowi, F dan Sufri, M. 2004. Manajemen Agribisnis. CV Baldad Grafitti Press. Palembang ISBN : 979-96207-1-6.

Soekanto,S. 1990. Sosiologi Suatu Pengantar. PT Rajawali. Jakarta

Soekartawi. 2005. Analisis Usahatani. UI Pres. Jakarta.

Soekartawi. 2004. Prinsip Dasar Ekonomi Pertanian. Raja Grafindo Persada. Jakarta

Subagyo, A. 2007. Studi Kelayakan Teori dan Aplikasi. PT Elex Media Komputindo Jakarta

Sudaryanto, T. Dan A. Munif. 2005. Pelaksanaan Revitalisasi Pertanian. Gramedia Pustaka Utama. Jakarta

Sugiyono (2009), Metode Penelitian Bisnis, CV. Alfabeta, Bandung.

Sunarto, K. 2001. Penagntar Sosiologi. Penerbit Fakultas Ekonomi. Universitas Indonesia. Jakarta

Suratiyah, Ken. 2006. Ilmu Usahatani. Cetakan I. Penerbit Penebar Swadaya. Jakarta.

Suryana. 2006. Kewirausahaan, Pedoman Praktis, Kiat dan Proses Menuju Sukses. Edisi Revisi Salemba Empat. Jakarta.

Suwandi. 2008. Memahami Penelitian Kualitatif. Rineka Cipta. Jakarta.

Tim Karya Tani Mandiri. 2010. Pedoman Budidaya Nanas. CV. Nuansa Aulia. Bandung.

Umar, H. 2002. Riset Pemasaran dan Perilaku Konsumen. PT. Gramedia Pustaka Utama. Jakarta. 